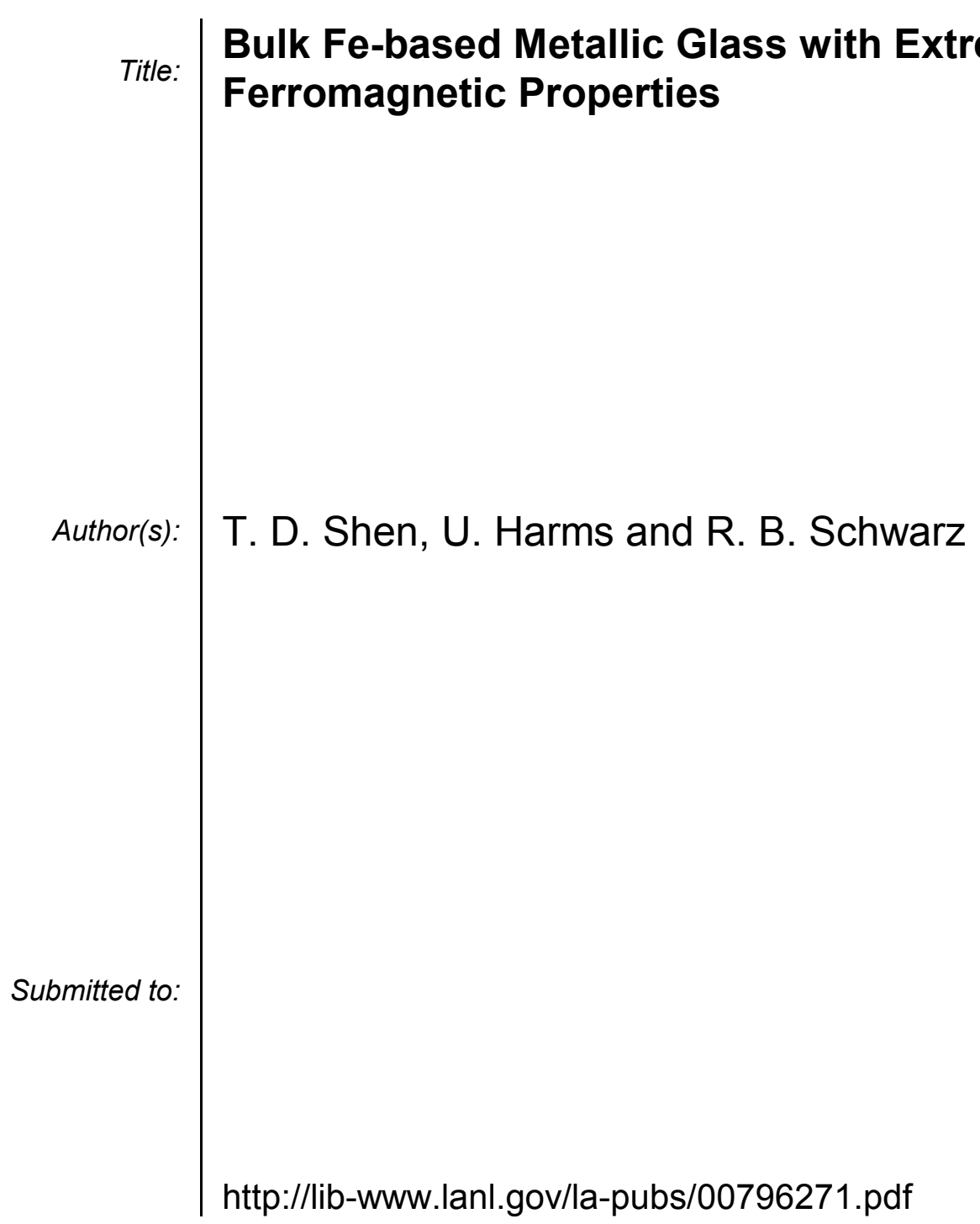

Los Alamos National Laboratory, an affirmative action/equal opportunity employer, is operated by the University of California for the U.S. Department of Energy under contract W-7405-ENG-36. By acceptance of this article, the publisher recognizes that the U.S. Government retains a nonexclusive, royaltyfree license to publish or reproduce the published form of this contribution, or to allow others to do so, for U.S. Government purposes. Los Alamos National Laboratory requests that the publisher identify this article as work performed under the auspices of the U.S. Department of Energy. Los Alamos National Laboratory strongly supports academic freedom and a researcher's right to publish; as an institution, however, the Laboratory does not endorse the viewpoint of a publication or guarantee its technical correctness. 
For rapid communication:

Tel: (505) 665-1171

Fax: (505) 667-8021

e-mail: TDShen@Lanl.Gov

\title{
Bulk Fe-based Metallic Glass with Extremely Soft Ferromagnetic Properties
}

\author{
T. D. Shen, U. Harms and R. B. Schwarz
}
Structure-Property Relations Group, MST-8, Mail Stop G755, Materials Science and Technology Division, Los Alamos National laboratory, Los Alamos, New Mexico 87545

Keywords: Bulk Ferromagnetic Glass, Magnetic Properties, Coercivity, Permeability, Power Losses, Anomalous Factor, $\mathrm{Fe}_{65.5} \mathrm{Cr}_{4} \mathrm{Mo}_{4} \mathrm{Ga}_{4} \mathrm{P}_{12} \mathrm{~B}_{5.5} \mathrm{C}_{5}$.

\begin{abstract}
We have investigated the DC and AC magnetic properties of a bulk glassy $\mathrm{Fe}_{65.5} \mathrm{Cr}_{4} \mathrm{Mo}_{4} \mathrm{Ga}_{4} \mathrm{P}_{12} \mathrm{~B}_{5.5} \mathrm{C}_{5}$ alloy. In the annealed state the alloy has coercivity $H_{C}$ and maximum DC permeability $\mu_{m}$ of approximately $0.4 \mathrm{~A} / \mathrm{m}(5 \mathrm{mOe})$ and $2.8 \times 10^{5}$, comparable to those found in annealed zero-magnetostriction Co-based alloys. The low $H_{C}$ found in our bulk glassy alloy is attributed to the low ratio of surface-roughness to sample thickness, and low residual internal-stress. The total power loss in our annealed bulk glass is about one order of magnitude lower than that of rapidly quenched Fe-based glassy ribbons. This is attributed to a low anomalous eddy-current loss.
\end{abstract}

\section{Introduction}

Since the discovery of soft magnetic properties in amorphous ferromagnetic materials, researchers have been interested in the possibility of using these alloys in the manufacture of power transformers and motors [1]. The motivation is based on the fact that cores built from glassy alloys may reduce the core losses under $\mathrm{AC}$ excitation by as much as $70 \%$. Conventional metallic glasses are prepared by quenching the melt at cooling rates on the order of $10^{6} \mathrm{~K} / \mathrm{s}$. Because of this high cooling rate, the glassy alloys could only be fabricated in the form of thin foils, typically 25 to 40 $\mu \mathrm{m}$ thick. The commercial implementation of these thin foils into transformers and motors has been slow due to cost of manufacture, thinness of gauge, and stress sensitivity. The thinness of gauge decreases the density of the core because air gaps are left between the large number of foils needed to build up the core. Low-density cores cause an unnecessary increase in the length of the copper windings, increasing the ohmic losses of the transformers and lowering their efficiency. The cores of medium-size transformers are usually constructed by wounding the thin foils because it is difficult to stack them using the well-established lamina interleaving techniques developed for the 0.3-mm-thick crystalline Fe-Si laminas. The recent discovery [2,3] of bulk ferromagnetic metallic glasses may solve some of these problems. In this paper we report the $\mathrm{DC}$ and $\mathrm{AC}$ magnetic properties of bulk glassy $\mathrm{Fe}_{65.5} \mathrm{Cr}_{4} \mathrm{Mo}_{4} \mathrm{Ga}_{4} \mathrm{P}_{12} \mathrm{~B}_{5.5} \mathrm{C}_{5}$ alloys.

\section{Experimental Procedures}

Glassy rods with a diameter of $4 \mathrm{~mm}$ were prepared by a flux-melting and water-quenching technique. The details of this technique have been published elsewhere [2]. The magnetic properties were measured on a toroid cut from the bulk glassy rod using a diamond-impregnated drill and a diamond-impregnated wire saw. The outside and inside diameters of the toroid are 3.91 and 2.49 $\mathrm{mm}$ respectively. This toroid had a rectangular cross-section of $0.71 \mathrm{~mm}$ wide and $0.97 \mathrm{~mm}$ high. The toroid was isothermally annealed at $400{ }^{\circ} \mathrm{C}$ in high-purity argon. After annealing the toroid was furnace cooled over a two-hour period. Primary and secondary coils were wound on the toroid using enamel-coated copper wire. The DC and AC magnetic properties of the toroid were characterized in a SMT-600 Magnetic Hysteresigraph (Magnetic Instrumentation Inc, Indianapolis, Indiana 46250). 


\section{Results}

Fig. 1 shows the cyclic $B-H$ curve for the bulk glassy $\mathrm{Fe}_{65.5} \mathrm{Cr}_{4} \mathrm{Mo}_{4} \mathrm{Ga}_{4} \mathrm{P}_{12} \mathrm{~B}_{5.5} \mathrm{C}_{5}$ toroid annealed at $400{ }^{\circ} \mathrm{C}$ for 16 hours. For comparison, this figure also shows the $B-H$ curve for an annealed zero-magnetostriction $\left(\lambda_{S}\right)$ glassy $\mathrm{Co}_{67.4} \mathrm{Fe}_{4.1} \mathrm{Ni}_{3} \mathrm{Mo}_{1.5} \mathrm{~B}_{12.5} \mathrm{Si}_{11.5}$ alloy ribbon [4]. The bulk glassy alloy exhibits extremely soft ferromagnetic properties, comparable to those for the annealed zero- $\lambda_{S}$ Co-based glassy ribbon. The coercivity $H_{C}$ measured at an applied field of $24 \mathrm{~A} / \mathrm{m}$ is 0.35 $\mathrm{A} / \mathrm{m}(0.0044 \mathrm{Oe})$, which is $70 \%$ of the $H_{C}$ in the zero- $\lambda_{S}$ Co-based alloy.

Isothermal annealing influences the DC magnetic properties of our bulk glassy alloy. Fig. 2 shows the dependence of the corecivity, $H_{C}$, and of the maximum DC permeability, $\mu_{m}$, on annealing time. After a 16-hour anneal at $400^{\circ} \mathrm{C}\left(60^{\circ} \mathrm{C}\right.$ below glass-transition temperature, $\left.T_{g}\right), H_{C}$ decreased by a factor of 7 whereas $\mu_{m}$ increased by a factor of 20 , reaching approximately $2.8 \times 10^{5}$.

Fig. 3 shows the dependence of the AC power losses on annealing time at $400{ }^{\circ} \mathrm{C}$. The two curves shown are for frequencies of 50 and $1000 \mathrm{~Hz}$. At both frequencies the AC power losses decrease rapidly within the first four hours of annealing to a value approximately one third that for the as-quenched sample. Further annealing does not significantly change the AC power losses.

Fig. 4 displays the dependence of the AC power losses at a frequency of $50 \mathrm{~Hz}$ on the maximum induction, $B_{m}$. The figure compares the AC power losses in our bulk glass with those reported in the literature [5] for three $100 \mu \mathrm{m}$-thick ribbons of the following materials: crystalline $\mathrm{Fe}-6.5 \mathrm{wt} \% \mathrm{Si}$, glassy $\mathrm{Fe}_{78} \mathrm{Si}_{9} \mathrm{~B}_{13}$, and glassy $\mathrm{Fe}_{77} \mathrm{Al}_{2.14} \mathrm{Ga}_{0.86} \mathrm{P}_{8.4} \mathrm{C}_{5} \mathrm{~B}_{4} \mathrm{Si}_{2.6}$ ribbons. Annealing decreases the total power losses in our alloy by approximately a factor of 4 . Notice that the power losses in our annealed bulk glassy alloy are approximately one order of magnitude lower than those of crystalline $\mathrm{Fe}-6.5 \mathrm{wt} \% \mathrm{Si}$ and glassy $\mathrm{Fe}_{78} \mathrm{Si}_{9} \mathrm{~B}_{13}$.

\section{Discussions}

\subsection{Properties}

The coercivity and maximum DC permeability of the present bulk glass are comparable to those of annealed zero-magnetostriction Co-base glassy ribbon. This is in spite of the fact that our glassy alloy has a much larger saturation-magnetostriction, of approximately $15 \times 10^{-6}$ [6]. The value of $H_{C}$ depends mostly on the surface and volume pinning of magnetic domain walls. It has been reported [7] that $H_{C}$ due to surface irregularities is proportional to the ratio of the surface-roughness amplitude to specimen thickness. This contribution to $H_{C}$ should be rather low in our toroid because (1) it was finely polished with $0.3 \mu \mathrm{m}$ diamond paste and (2) it had an effective thickness significantly larger than that of rapidly quenched glassy ribbons. The contribution to $H_{C}$ due to volume pinning results from the presence of internal stress. This contribution is proportional to the product of saturation magnetostriction and the amplitude of stress fluctuations [8]. This $H_{C}$ contribution should also be low in our toroid because of the relatively slow cooling-rate during manufacture and subsequent thermal annealing at $T \approx T_{g}-60{ }^{\circ} \mathrm{C}$.

\subsection{AC Properties}

The total power losses per cycle $\left(W_{t}\right.$, in units of $\mathrm{J} / \mathrm{kg}$ ) are attributed to hysteresis $\left(W_{h}\right)$, classical eddy-current ( $\left.W_{e}\right)$, and anomalous (or excess) eddy-current $\left(W_{a}\right)$ losses respectively [9]:

$$
W_{t}=W_{h}+W_{e}+W_{a}
$$

Multifying Eq. (1) by frequency $f$, the total power losses $\left(P_{t}\right.$, in units of $\mathrm{W} / \mathrm{kg}$ ) can be written as

$$
P_{t}=P_{h}+P_{e}+P_{a}=W_{h} f+P_{e}+P_{a}
$$




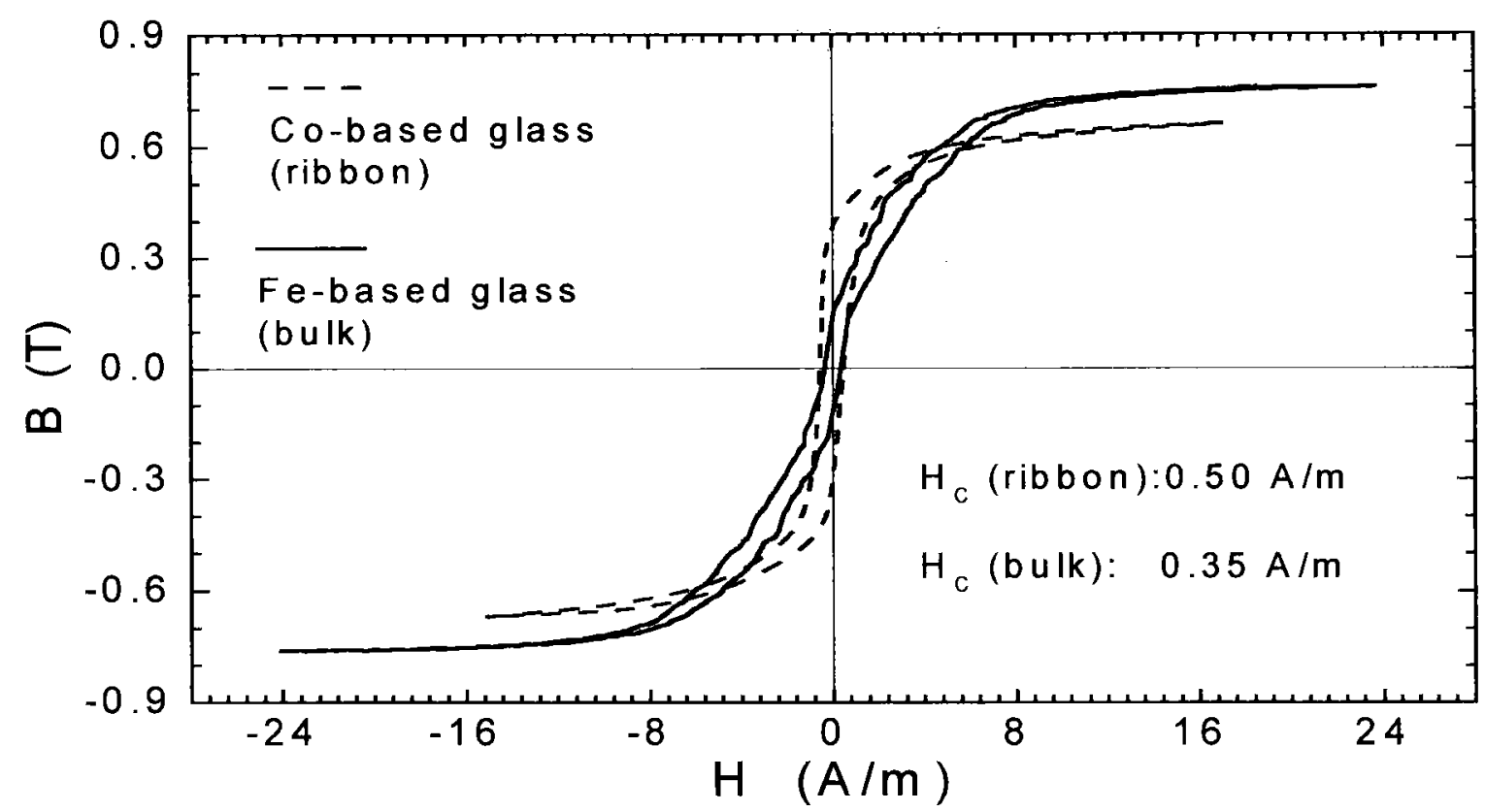

Fig. 1. Cyclic $B-H$ curves for bulk glassy $\mathrm{Fe}_{65.5} \mathrm{Cr}_{4} \mathrm{Mo}_{4} \mathrm{Ga}_{4} \mathrm{P}_{12} \mathrm{~B}_{5.5} \mathrm{C}_{5}$ isothermally annealed at $400{ }^{\circ} \mathrm{C}$ for $16 \mathrm{hrs}$, and for annealed $\mathrm{Co}_{67.4} \mathrm{Fe}_{4.1} \mathrm{Ni}_{3} \mathrm{Mo}_{1.5} \mathrm{~B}_{12.5} \mathrm{Si}_{11.5}$ glassy ribbon.

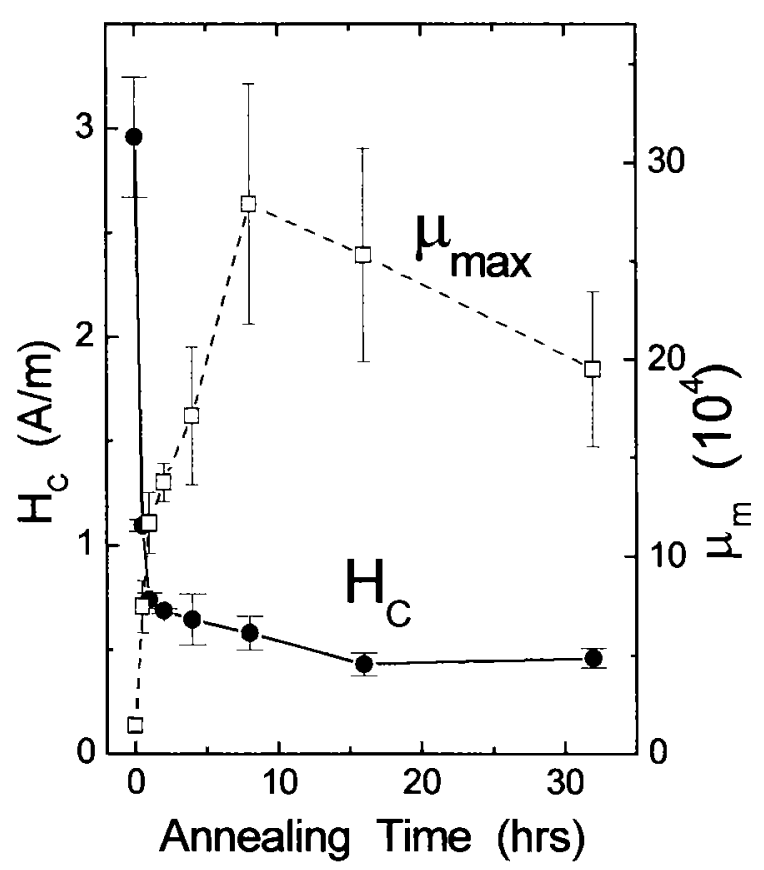

Fig. 2. Dependence of the maximum DC permeability ( $\square$ ) and coercivity $(\bullet)$ of bulk glassy $\mathrm{Fe}_{65.5} \mathrm{Cr}_{4} \mathrm{Mo}_{4} \mathrm{Ga}_{4} \mathrm{P}_{12} \mathrm{~B}_{5.5} \mathrm{C}_{5}$ alloy on annealing time at $400{ }^{\circ} \mathrm{C}$.

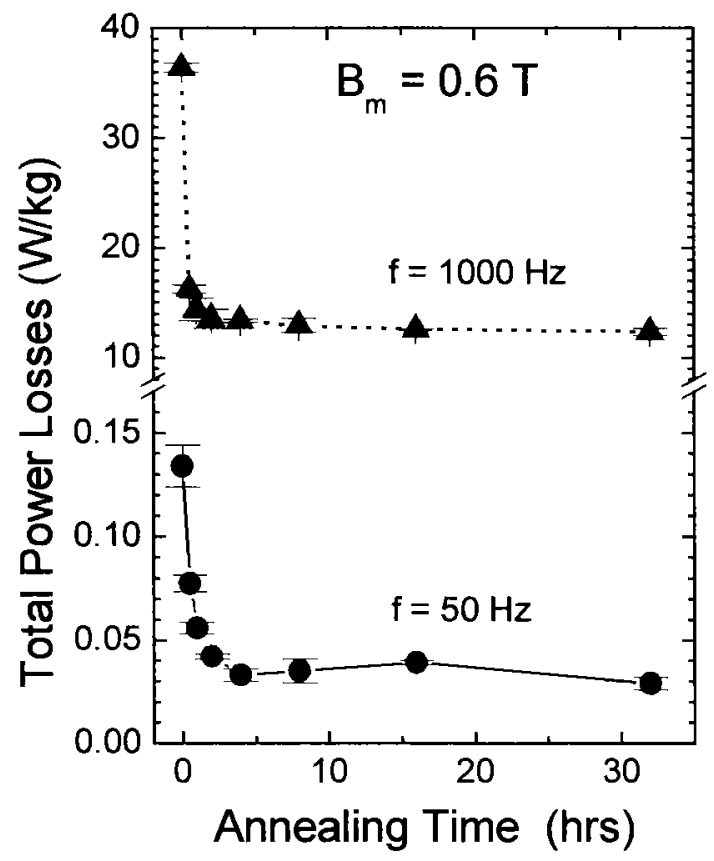

Fig. 3. Dependence of total power losses on annealing time at $400{ }^{\circ} \mathrm{C}$ for bulk glassy $\mathrm{Fe}_{65.5} \mathrm{Cr}_{4} \mathrm{Mo}_{4} \mathrm{Ga}_{4} \mathrm{P}_{12} \mathrm{~B}_{5.5} \mathrm{C}_{5}$ alloy measured at $50 \mathrm{~Hz}(\bullet)$ and $1000 \mathrm{~Hz}(\boldsymbol{\Delta})$. 


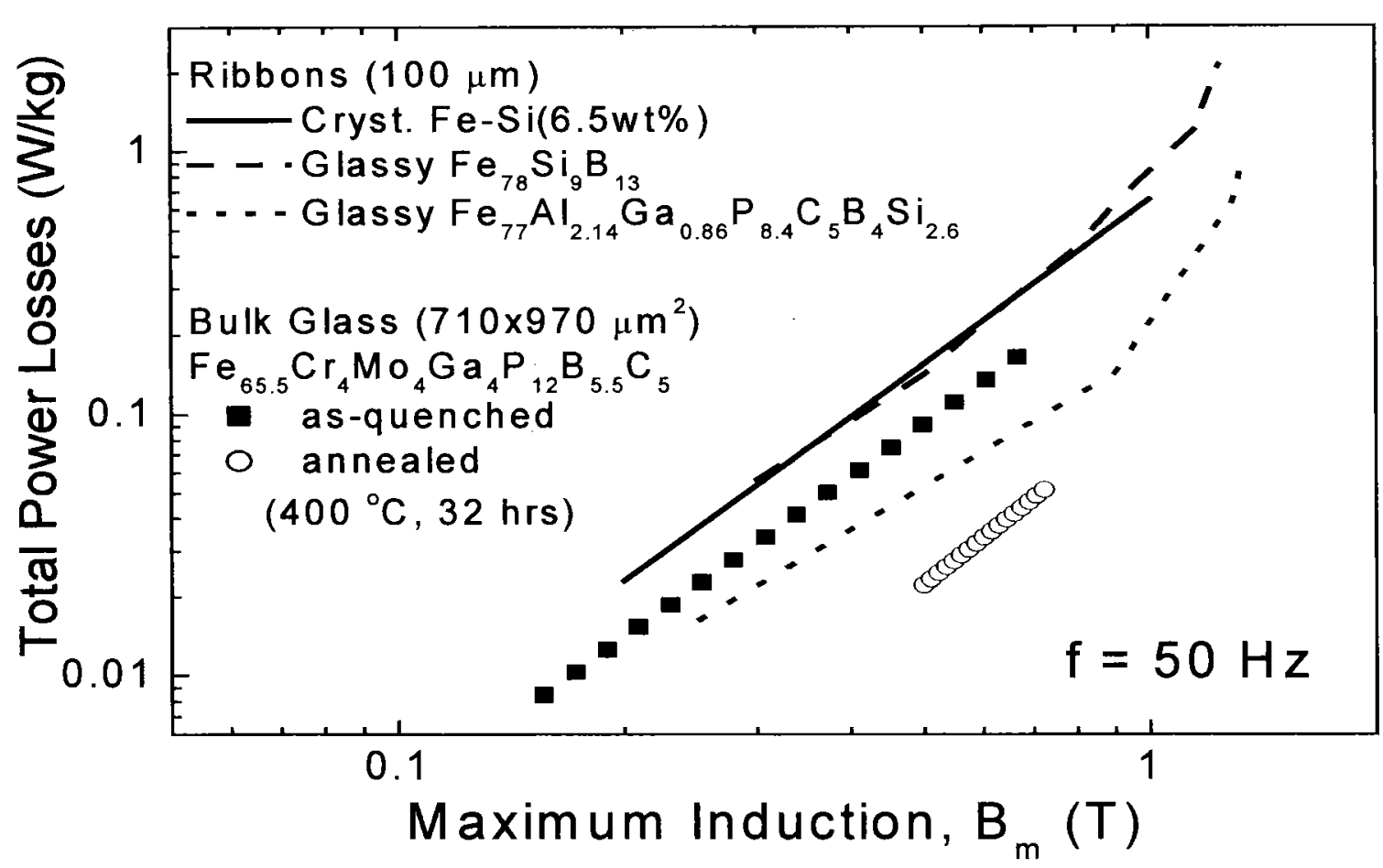

Fig. 4. Total power losses as a function of maximum induction $B_{m}$, measured at a frequency of $50 \mathrm{~Hz}$, for thin crystalline Fe-Si (solid line), glassy ribbons (dashed and dotted lines), and the present bulk glass in the as-quenched $(\boldsymbol{})$ and annealed $(0)$ states.

In Eq. (2) the hysteresis losses $W_{h}$ are assumed to be frequency independent and can thus be obtained by measuring the total losses over a frequency range and extrapolating to $f=0$. The classical eddy current losses, $P_{e}$, have the general form [10]

$$
P_{e}=\frac{\left(\pi f B_{m} d\right)^{2}}{\beta R \rho}
$$

where $d$ is the effective dimension, $R$ is the bulk resistivity, $\rho$ is the density, and $\beta$ is a geometrical coefficient. For laminas of thickness $d, \beta=6$. This $\beta$ value is applicable to the toroids made from rapidly quenched thin glassy foils. For cylinders of diameter $d, \beta=16$. For spheres of diameter $d$, $\beta=20$.

For our toroid of rectangular cross-section, with width $w$ and height $h$, we use [11]

$$
\beta=\frac{6}{1-0.633 \frac{w}{h} \tanh \left(1.58 \frac{h}{w}\right)}
$$

For $w<h$, Eq. (4) gives $\beta=6$, which is just the value for laminas. For $w=h$, Eq. (4) gives $\beta=14.3$, which is also a reasonable value compared to the $\beta$ value of 16 for cylinders.

The difference $W_{t}-W_{h}-W_{e}$ defines the anomalous losses, $W_{a}$. This decomposition usually shows that $W_{a}$ depends linearly on frequency. Fig. 5 shows $W_{h}, W_{e}$, and $W_{a}$ for our bulk glassy toroid. The $W_{h}$ value is similar to that measured in glassy ribbons. Because the thickness of 


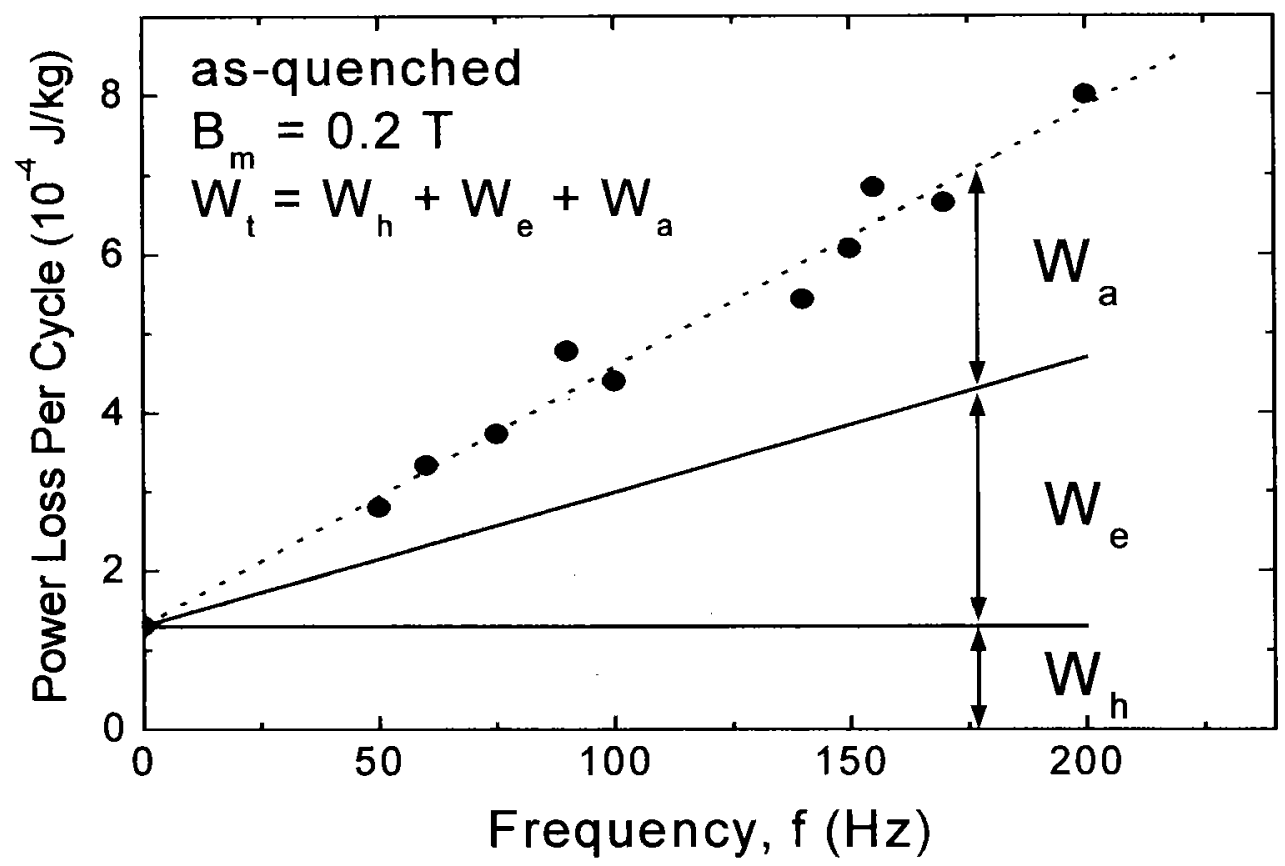

Fig. 5. Frequency dependence of total power losses (•) in as-quenched bulk glassy $\mathrm{Fe}_{65.5} \mathrm{Cr}_{4} \mathrm{Mo}_{4} \mathrm{Ga}_{4} \mathrm{P}_{12} \mathrm{~B}_{5.5} \mathrm{C}_{5}$ measured at maximum induction $B_{m}$ of $0.2 \mathrm{~T}$. The total losses are separated into hysteresis $\left(W_{h}\right)$, classical eddy-current $\left(W_{e}\right)$, and anomalous eddy-current $\left(W_{a}\right)$ contributions.
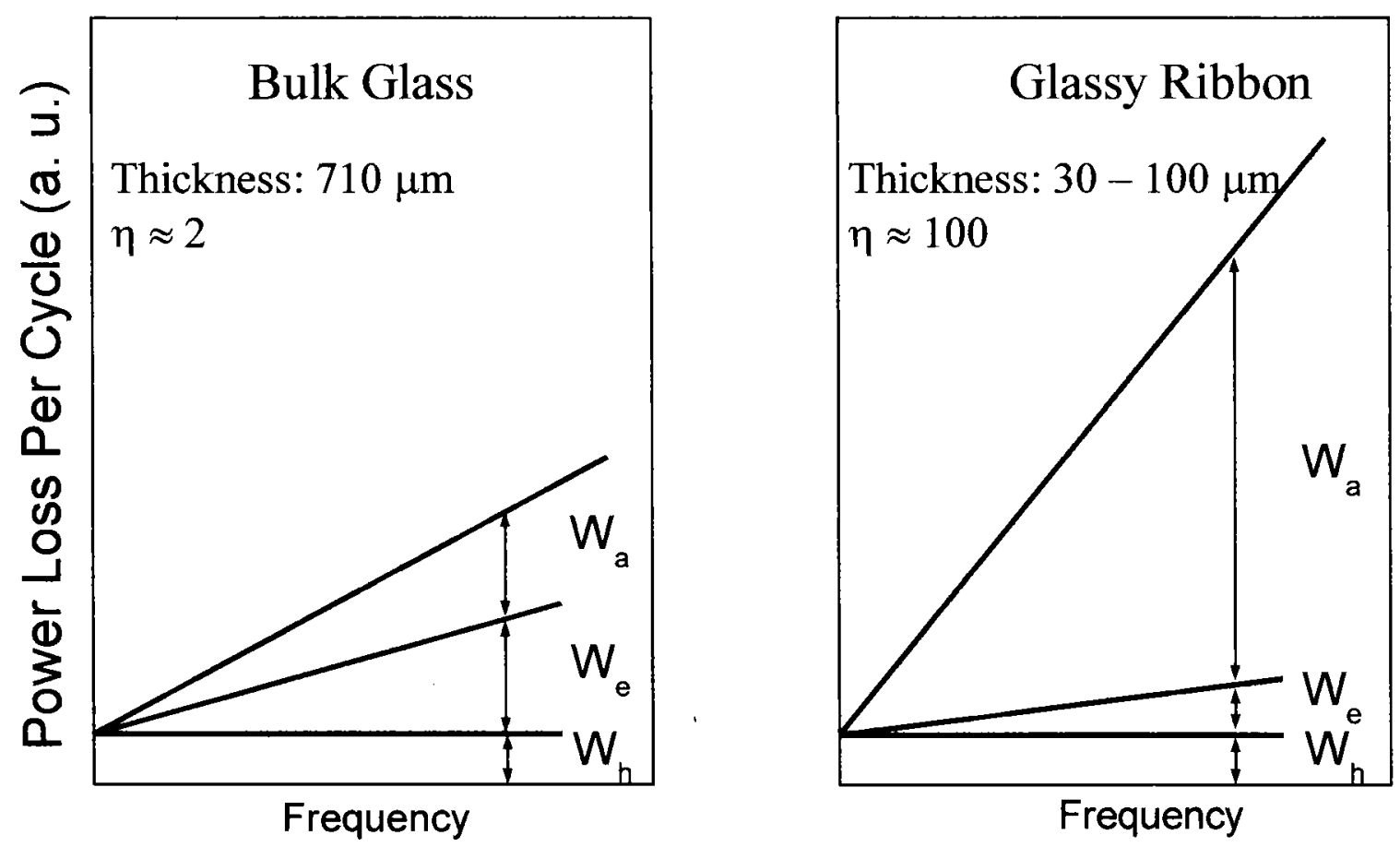

Fig. 6. Schematic representation of the $W_{h}, W_{e}$, and $W_{a}$ contributions to the total power losses in bulk glass and in glassy ribbon. 
our toroid exceeds that of the glassy ribbons by about one order of magnitude, according to Eqs. (3) and (4), the $W_{e}$ value for the present toroid should exceed that for glassy ribbons by two orders of magnitude. One may argue that this should limit the applicability of bulk ferromagnetic glasses. However, our bulk glass has a very low value of $W_{a}$. In contrast to glassy ribbons, where $W_{a}$ is usually about two orders of magnitude larger than $W_{e}[9,12]$, in our bulk glass $W_{e} \approx W_{a}$.

Fig. 6 shows schematically the relative values of $W_{h}, W_{e}$ and $W_{a}$ in our bulk ferromagnetic glass and in the rapidly quenched glassy ribbons. The anomalous factor, defined as $1+W_{a} / W_{e}$, for our bulk glass is about 2 , which is significantly smaller than the value of approximately 100 found for glassy ribbons.

\section{Conclusions}

The coercivity and permeability of bulk Fe-based metallic glass prepared by a flux-melting and water-quenching technique are comparable to those of the more expensive zeromagnetostriction Co-based glasses. This is due to the low surface-roughness, large specimenthickness, and low residual internal-stress in our alloy. The total power losses of our bulk Fe-based glass are significantly lower than those of rapidly-quenched Fe-based glassy ribbons. This is attributed to the low value of anomalous eddy current losses in our toroid. The origin of anomalous eddy current losses in ferromagnetic glassy alloys is presently not understood.

\section{Acknowledgements}

This work was supported by the U. S. Department of Energy, Office of basic Energy Sciences, Division of Materials Sciences. Technical assistance by Mr. Jose. I. Archuleta is gratefully acknowledged.

\section{References}

[1] F. E. Luborsky, IEEE Trans. Mag. 14 (9178), p. 1008.

[2] T. D. Shen and R. B. Schwarz, Appl. Phy. Lett. 75 (1999), p.49.

[3] T. D. Shen and R. B. Schwarz, Acta Mater. 49 (2001), p. 837.

[4] R. Hasegawa, J. Mag. Mag. Mater. 41 (1984), p. 79.

[5] T. Mizushima, A. Makino, S. Yoshida, and A. Inoue, J. Appl. Phys. 85 (1999), p. 4418.

[6] U. Harms, T. D. Shen, and R. B. Schwarz, unpublished results, Los Alamos National Laboratory (2001).

[7] F. E. Luborsky, Amorphous Metallic Alloys(edited by F. E. Luborski, Butterworths, London, 1983), chapter 19.

[8] A. H. Morrish, The Physical Principles of Magnetism(Robert E. Krieger Publishing Company, Huntington, 1980), chapter 7.

[9] See, for example, H. Pfützner, IEEE Trans. Mag. 27 (1991), p. 3426.

[10] D. Jiles, Introduction to Magnetism and Magnetic Materials (Chapman and Hall, London, 1991), chapter 12.

[11] R. Sikora, J. Purczyński, W. Lipiński, and M. Gramz, IEEE Trans. Mag. 14 (1978), p. 383.

[12] M. G. Blundell and K. J. Overshott, IEEE Trans. Mag. 16 (1980), p. 1224.

Correspondence: TDShen@Lanl.Gov 